LBL- -31075

DE92 000903

Microstructural Influence on the Work Hardening of Aluminum-Lithium Alloy 2090 at Cryogenic Temperatures

D. Chu, C. Tseng, and J.W. Morris, Jr.

\author{
Center for Advanced Materials \\ Materials and Chemical Sciences Division \\ Lawrence Berkeley Laboratory \\ 1 Cyclotron Road \\ Berkeley, CA 94720 \\ and \\ Department of Materials Science and Mineral Engineering \\ University of California
}

June 1991

This work was supported by the Director, Office of Energy Research,

Office of Basic Energy Science, Materials Sciences Division of the U.S.

Deparment of Energy under Contract No. DE-AC03-76SF00098. 


\title{
Microstructural Influence on the Work Hardening of Aluminum-Lithium Alloy 2090 at Cryogenic Temperatures
}

\author{
D. Chu, C. Tseng, and J.W. Morris, Jr. \\ Canter for Advanced Materials, Lawrence Berkeley I aboratory, and \\ Department of Materials Science and Mineral Engineering, \\ University of California, Berkeley
}

Previous studies indicate that the work hardening characteristics of a Vintage III 2090-T81 12.7-mm (0.5-in.) plate is highly dependent on the through-thickness position. $[1,2]$ This dependency has been linked to two distinctly different microstructures existing as laminates within the plate. [3] An investigation of the two microstructures by both optical and trarismission electron microscopy reveal a difference in the distribution of grains and subgrains. It is believed that these factors affect the work hardening characteristics by governing the manner in which slip is transmitted from grain to grain. The findings are positive as they suggest a practical means by which improvements in work hardening can be obtained through modifications of the microstructure at the polygranular level.

\section{Introduction}

Due to their potential as a structural material with lower density, higher stiffness and strength relative to current high strength aluminum alloys, $[4,5]$ aluminum-lithium alloys have become candidate materials for aerospace applications. ${ }^{[6,7]}$ One particular alloy which has received a great deal of attention in recent years is the Al- $\mathrm{Cu}-\mathrm{Li}-\mathrm{Zr}$ alloy 2090. Previous studies have revealed an excellent strength-toughness combination for 2090 at cryogenic temperatures. ${ }^{[6,8-13]}$ Subsequently, much of the work on 2090 has concentrated on understanding the source of the excellent mechanical properties observed at cryogenic temperatures. [1-3,6,8-14] Although the determining mechanism remains an issue of debate, it is generally agreed upon that the deformation behavior, the ability of a material to work harden, plays an important part in determining the subsequent fracture toughness. $[6,8,10,12]$ 
The majority of work on 2090 and other like alloys associates increases in work hardening with greater slip homogeneity. [15-17] Jata and Starke[16] relate this greater homogeneity with a decrease in slip planarity. The planarity of slip is, in turn, controlled by the ability of dislocations to cross-slip. Since cross-slip is a thermally activated process, it is sensitive to temperature and to solute atoms that interact with dislocations. When cross-slip is difficult, as it is at cryogenic temperatures, work hardening is expected to increase due to the decreased ability of a dislocation to bypass an impenetrable obstacle. Following this line of reasoning, the improved work hardening observed in 2090 and other aluminum-lithium alloys has been regarded as predominantly a temperature-induced phenomenon. $[6,8,10,16]$

General theories on work hardening atiribute work hardening to microstructural features at the dislocation level. Evidence of this can be found in studies of low carbon steel. $[18,19]$ Results suggest that for a certain temperature range, the flow stress in low carbon steels is controlled predominantly by the motion of screw dislocations and not by other larger microstructural features. ${ }^{[20]}$ The implications of this conclusion is not promising since it suggests that the work hardening, as it is controlled by dislocation motion, will remain unchanged despite further modifications of the polygranular structure.

Although the inability to influence the deformation behavior through manipulation of the polygranular structure may be true in some materials such as low carbon steel, this does not appear to be the case for aluminum-lithium alloys. Studies on a $12.7-\mathrm{mm}(0.5-$ in.) Vintage III 2090- 181 plate material ${ }^{[1-3]}$ reveal two distinctly different microstructures existing as individual laminates within the same plate. Tensile tests conducted on the two microstructures reveal a significant difference in the work hardening temperature response. $[2,3]$ This finding is both promising and potentially important as it implies that, at least for this alloy system, the work hardening is controlled to some extent by microstructural features at the polygranular level.

Ongoing research has continued with transmission electron microscopy toward understanding the microstructural source of the observed differences in work hardening. This paper reviews our current understanding and the results from preliminary microscopy studies.

\section{Experimental Procedure}

The material investigated in this study was a Vintage III 2090 plate that was provided by Alcoa in the form of a $12.7-\mathrm{mm}(0.5$-in.) plate in the $-\mathrm{T} 81$ condition (solution heat treated, stretched and peak-aged). This temper is also referred to as -T8E41 in earlier publications. The composition was determined by atomic absorption spectroscopy to be $\mathrm{Al}-3.05 \mathrm{Cu}-2.16 \mathrm{Li}-0.11 \mathrm{Zr}$. The process is a proprietary one that includes a thermomechanical reduction into plate form, a solution heat treatment, a subsequent 6 to 8 pct stretch, and a final peak age at $163^{\circ} \mathrm{C}$ for approximately 24 hours. 
Mechanical tests were done at one of four temperatures: $300 \mathrm{~K}$ (room temperature), $200 \mathrm{~K}$ (dry ice and alcohol), $77 \mathrm{~K}$ (liquid nitrogen), or $4 \mathrm{~K}$ (liquid helium). Tests were performed in servohydraulic testing machines equipped for cryogenic testing. Details of the data collection and analysis are documented in earlier papers. $[1-3]$

The as-received microstructure was examined by both optical microscopy and transmission electron microscopy (TEM). The areas examined were selected from the regions corresponding to mid-thickness and quarter-thickness of the plate. Optical samples were polished to $0.05 \mu \mathrm{m}$ and etched using Keller's reagent $\left(2.5\right.$ pct $\mathrm{HNO}_{3}, 1.5 \mathrm{pct} \mathrm{HCl}$, $0.5 \mathrm{pct} \mathrm{HF}(40 \mathrm{pct})$, balance $\mathrm{H}_{2} \mathrm{O}$ ) for approximately 30 seconds. Corresponding TEM samples were prepared by mechanically grinding to $0.25 \mathrm{~mm}(0.010 \mathrm{in}$.) and punching out 3-mm disks. The disks were electropolished with the double jet technique at $-30^{\circ} \mathrm{C}$ in a 4:1 mixture of methanol and nitric acid. The polishing condition was set at 18 to $20 \mathrm{~V}$.

\section{Results and Discussion}

A complete tabulation of the measured mechanical properties from both tensile tests and fracture toughness tests can be found in an earlier publication. ${ }^{23}$ Those pertinent to the present discussion are highlighted here.

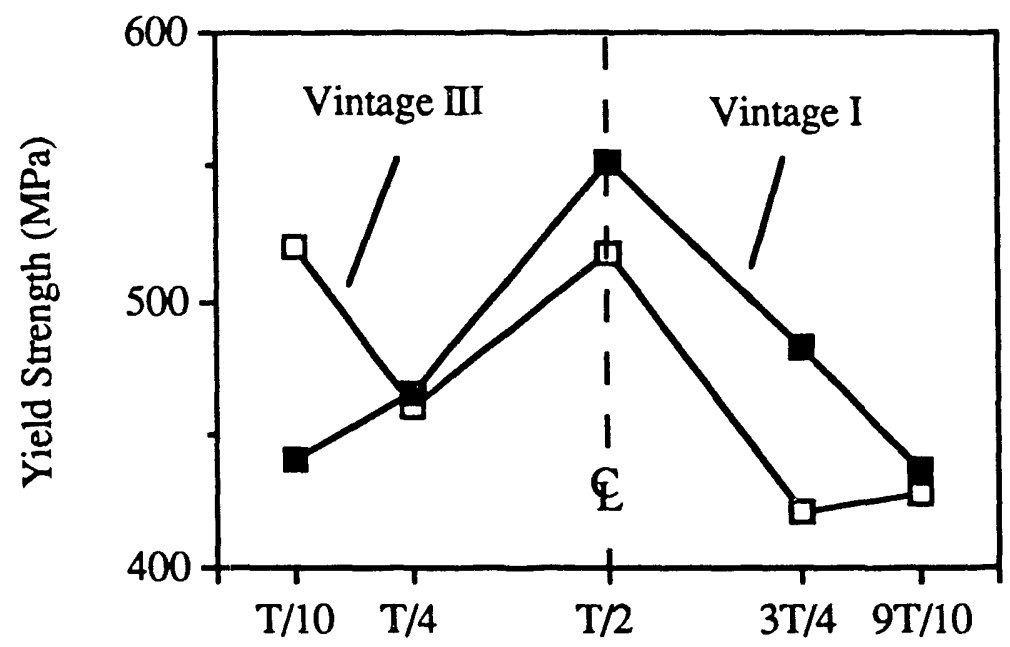

Figure 1: Comparison of the longitudinal yield strength as a function of the through-thickness position for Vintage I and Vintage III $2090-\mathrm{T} 81$ at $300 \mathrm{~K}$.

Figure 1 plots the yield strength as a function of test temperature and distance from the centerline of the Vintage III 2090-T81 plate material. This profile is an improvement over the yield strength profile exhibited by its predecessor, Vintage I 2090, which decreases monotonically from mid-thickness to both surfaces. ${ }^{[21-24]}$ Earlier work has 
related the parabolic yield strength profile associated with Vintage I 2090 to a paralle] variation in the amount of hot-rolled texture components. ${ }^{[22,23]}$ Despite the variation in texture found in Vintage I 2090, the temperature response of the work hardening remains independent of the through-thickness position. Although the absolute values differ, work hardening curves obtained from tensile specimens at differing through-thiciness positions exhibit a steady and monotonic increase with decreasing temperature, as depicted schematically in Figure 2.

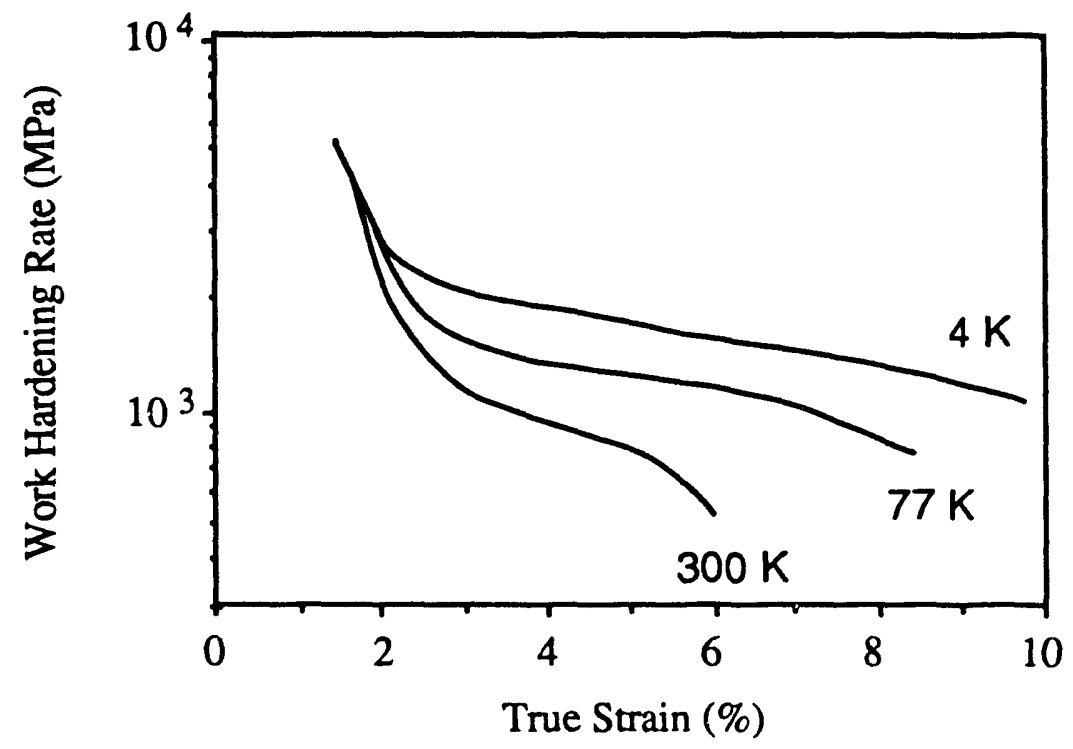

Figure 2: Schematic showing the improvement in work hardening with decreasing temperature in Vintage I 2090.

The most striking difference observed resides in the temperature response of the work hardening at mid-thickness and quarter-thickness in the Vintage III material. The improvement in the work hardening with decreasing temperature at mid-thickness is similar to that observed in the Vintage I material, as depicted in Figure 3a. In contrast, work hardening plots obtained from quarter-thickness exhibit little to no improvement with decreasing temperature until $4 \mathrm{~K}$ (Figure $3 \mathrm{~b}$ ). Since both regions are extracted from the same plate, they receive the same heat treatment and contain the same composition and intragranular microstructure. Subsequently, differences in the work hardening characteristic must lie at the polygranular level.

An optical study reveals that such a polygranular difference does exist. Figure 4 displays the microstructure at mid-thickness (Figure 4a) and quarter-thickness (Figure 4b). Although varying grain sizes are observed at mid-thickness, the average grain size is still significantly smaller than that within the quarter-thickness region. A difference in subgrain development is also revealed in Figure 4; the mid-thickness region exhibits a strong distribution of subgrains compared to quarter-thickness. 
Chu, Tseng, and Morris: Microstructural Influence on the Work Hardening of Aluminum-Lithium Alloy 2090 at Cryogenic Temperatures
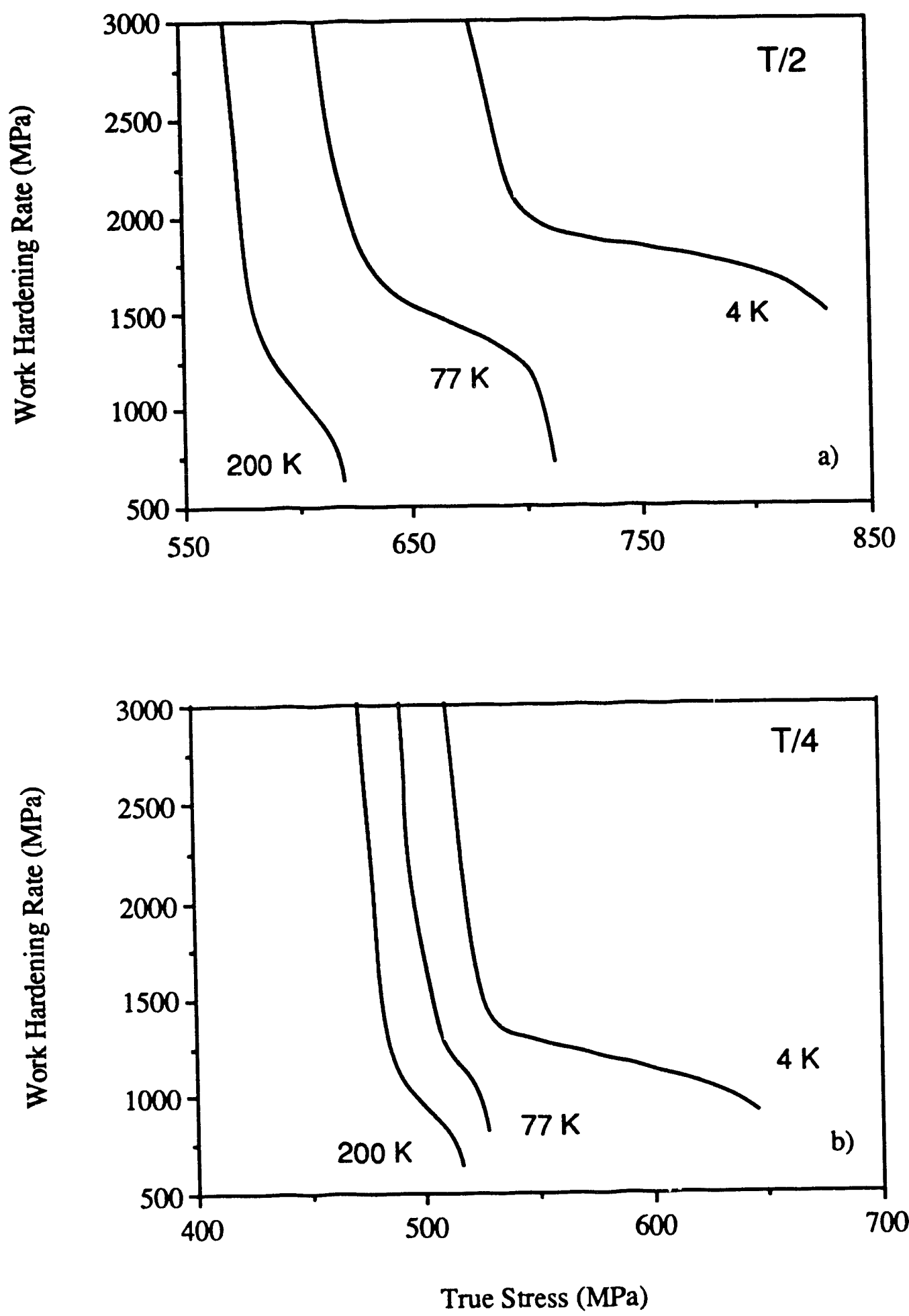

Figure 3: Temperature variation of the work hardening rate as a function of true stiess for 2090-T81 at a) mid-thickness and b) quarter-thickness. 


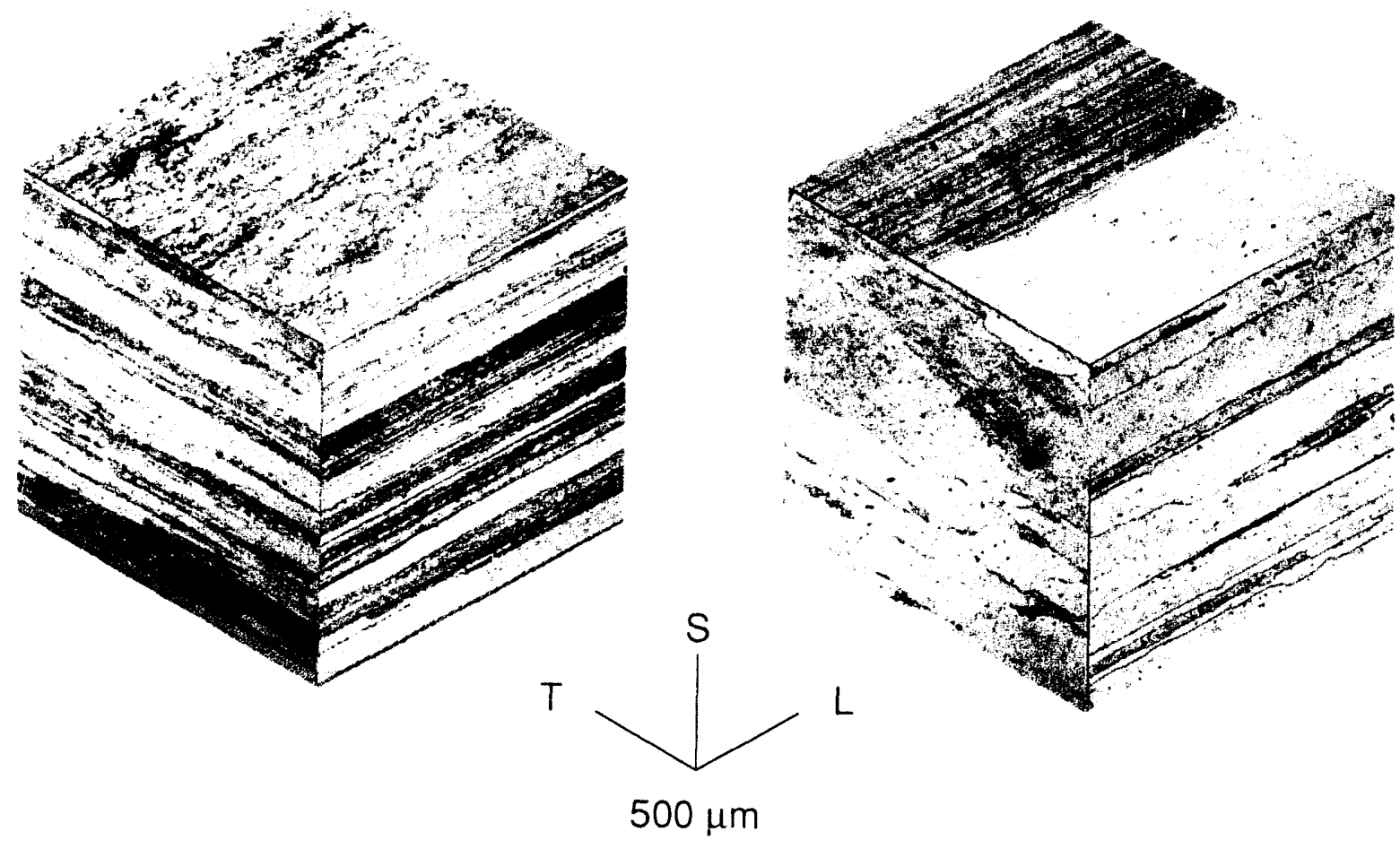

Figure 4: Optical micrograph of the microstructure at mid-thickness (on left) and quarter-thickness ion right). (XBB 915-3801)

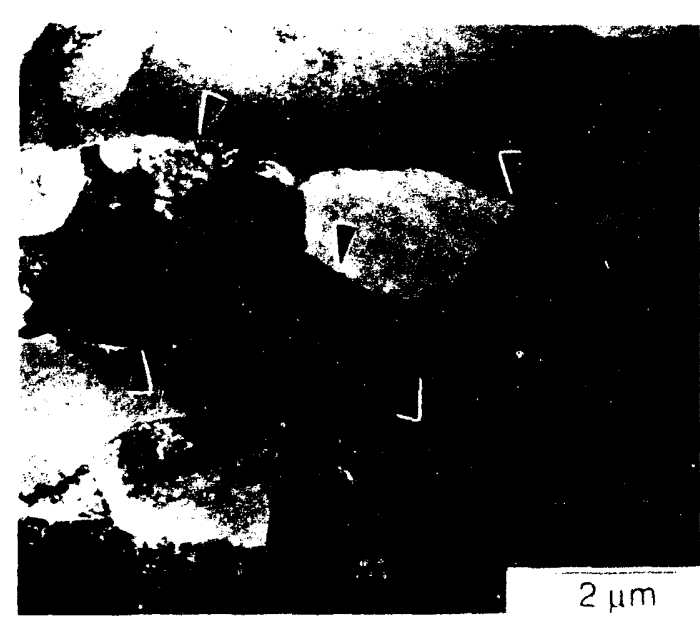

a)

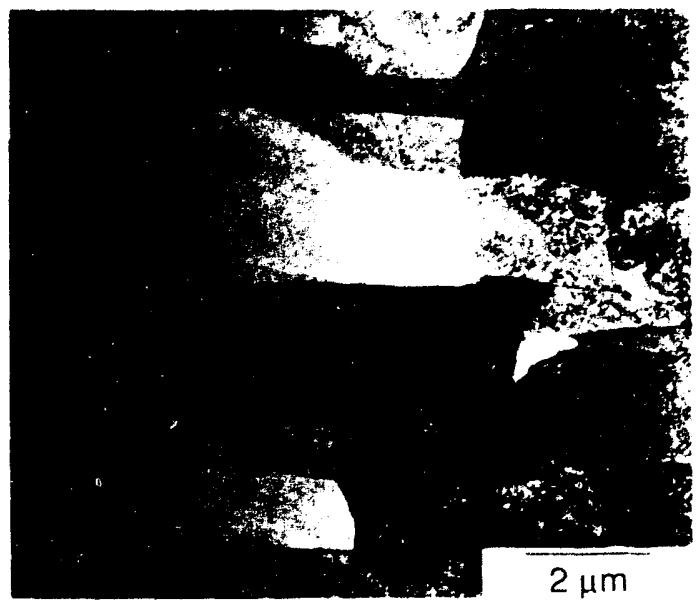

b)

Figure 5: TEM micrograph of the grain structure at mid-thickness. Note the extensive and homogeneous subgrain formation within a) one grain and b) several grains (grain boundaries denoted by arrows). (XBB 915-4155) 
Chu, Tseng, and Morris: Microstructural Influence on the Work Hardening of Aluminum-Lithium Alloy 2090 at Cryogenic Temperatures

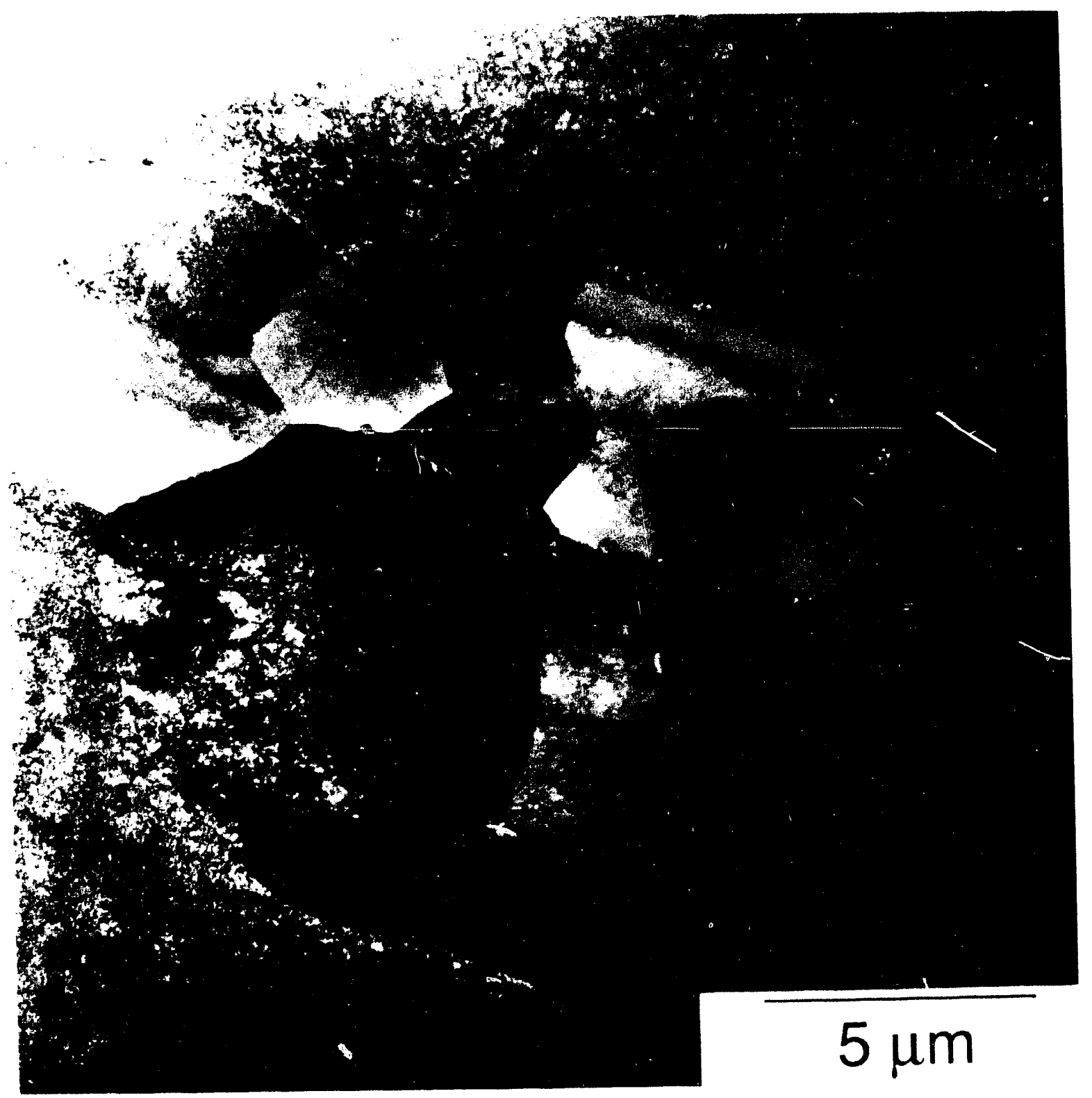

Figure 6: TEM micrograph of the grain structure at quarter-thickness. Note the inhomogeneous distribution of subgrains. Isolated grains composed of subgrains are found between large grains that do not contain subgrains. (XBB 915-4150) 
Results from preliminary TEM studies lend further support to the observations made by optical microscopy. Samples in the longitudinal plane of the as-received material show that the two regions differ in subgrain distribution and grain morphology. Extensive subgrain formation is observed in the mid-thickness region as shown in Figure 5 . The subgrains are homogeneously distributed, despite a relatively large range of grain thicknesses exhibited at this region; this grain thickness variation has been mentioned above (Figure 4). Figure 5 illustrates the subgrain formation at mid-thickness within one of the thicker giains (Figure 5a) and within a collection of thinner grains (Figure 5b). At quarterthickness, however, subgrain formation is limited and inhomogeneously distributed (Figure 6); isolated grains composed of subgrains are found between large grains that do not contain subgrains.

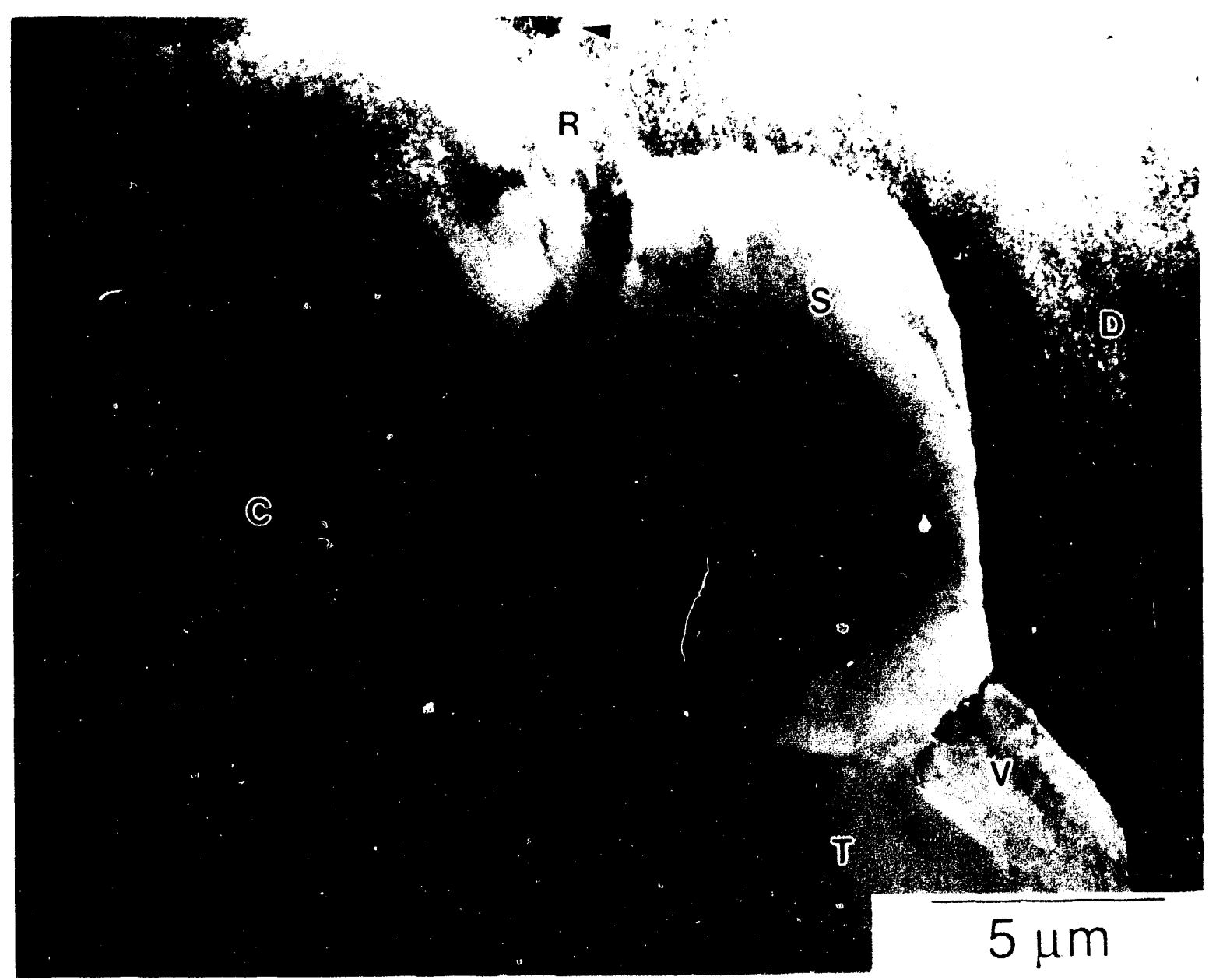

Figure 7: TEM micrograph at quarter-thickness showing the formation of small grains ( $R, S, T, V)$ between large grains (C and $D)$. The original grain boundary is denoted by an arrow. (XBB 915-4151) 
The grain size/shape distributions in the two regions are also dissimilar. Flat and elongated grains are seen at mid-thickness (Figures 5a and 5b). As previously discussed, these grains also vary in thickness. In contrast, the quarter-thickness grains appear more equiaxed and possess a greater variation in grain size (Figures 6 and 7) than those in Figure 5b. Smaller grains such as $R$ and $S$ are typically surrounded by large grains ( $C$ and $D$ ) in this region (Figure 7). Many of these smaller grains are situated between large grains (Figure 7).

The microstructural differences discussed above will undoubtedly affect the volume fraction of grain boundaries. In addition, the degree of grain and subgrain boundary misorientation should also be affected. It appears that these features play a strong role in determining the work hardening behavior, all other intragranular features are ruled out since the two microstructures contain the same constituents and receive the same aging treatment. It is speculated that the grain and subgrain boundaries dictate the work hardening behavior by governing the manner by which slip is transmitted from grain to grain. Evidence of such an interplay has been observed through an optical slip-relief study where greater elongations are found to be coupled with a greater tendency for out-of-plane rotation of subgrains. [14]

The results accumulated and discussed above are promising as they imply that a practical means may exist by which improvements in the work hardening behavior can be obtained through selected modifications of the polygranular microstructure. Continuing TEM studies on both as-received and prestrained specimens will attempt to verify and establish that aspect of the microstructure responsible for controlling the work hardening behavior.

\section{Conclusion}

Preliminary microscopy studies on the two microstructures evidenced in the alloy Vintage III 2090-T81 reveal a difference in the size and distribution of grains and subgrains. These differences in the polygranular structure are believed to be partially responsible for the varying temperature responses observed in the work hardening characteristic. It is speculated that the degree of grain boundary misorientation may also be important. The microstructural influence on the work hardening at the polygranular level implies the existence of an achievable means by which the work hardening and, to some extent, the subsequent strength and toughness can be controlled by modifications of the grain structure.

\section{Acknowledgements}

The authors thank the Alcoa Technical Center for providing the materials for this research. This study was supported by the Director, Office of Energy Research, Office of Basic Energy Science, Material Sciences Division of the U.S. Department of Energy under Contract No. DE-AC03-76SF00098. D. Chu was supported under a National Science Foundation Graduate Fellowship for the entire period of this work. 


\section{References}

1. D. Chu and J.W. Morris, Jr., Metall. Trans. A, to be published Aug 1991.

2. D. Chu: Master's Thesis, LBL 30170, University of California, Berkeley, CA, Dec. 1990.

3. D. Chu and J.W. Morris, Jr.: in "Light Weight Alloys for Aerospace Applications", E.W. Lee, ed., TMS, Warrendale, PA, 1991.

4. E.S. Balmuth and R. Schmidt: in Aluminum-Lithium Alloys, T.H. Sanders, Jr. and E.A. Starke, Jr. eds., TMS-AIME, New York, NY, 1981, pp. 69-88.

5. G.H. Narayanan, B.L. Wilson, W.E. Quist, and A.L. Wingert: Technical Report No. D6-51411, The Boeing Company, Seattle, WA, Aug. 1982.

6. J. Glazer: Ph.D. Thesis, LBL-27607, University of California, Berkeley, CA, July 1989.

7. W.E. Quist and G.H. Narayanan: in Treatise on Materials Science and Technology: Aluminum Alloys - Contemporary Research and Applications, A.K. Vasudevan and R.D. Doherty, eds., Academic Press, Inc., San Diego, CA, 1989, vol. 31, p. 219-54.

8. J. Glazer, S.L. Verzasconi, E.N. Dalder, W. Yu, R.A. Emigh, R.O. Ritchie, and J.W. Morris, Jr.: Adv. Cryog. Eng., 1986, vol. 32, pp. 397-404.

9. R.C. Dorward: Scripta Metall., 1986, vol. 20, pp. 1379-83.

10. J. Glazer, S.L. Verzasconi, R.R. Sawtell, and J.W. Morris, Jr.: Metall, Trans. A 1987, vol. 18A, pp. 1695-701.

11. D. Webster: Metall. Trans. A, 1987, vol.18A, pn. 2181-93.

12. K.T.V. Rao, W. Yu, and R.O. Ritchie: Metall. Trans. A, 1989, vol. 20A, pp. 485-97.

13. K.T.V. Rao and R.O. Ritchie: Acta Metall. Mater., 1990, vol. 38, pp. 2309-26.

14. D. Yao, D. Chu, and J.W. Morris, Jr.: in Light Weight Alloys for Aerospace Applications, E.W. Lee, ed., TMS, Warrendale, PA, 1991.

15. A.H. Cottrell and R.J. Stokes: Proc. Roy. Soc. A, 1955, vol. 233, pp. 17-34.

16. K.V. Jata and E.A. Starke, Jr.: Scripta Metall., 1988, vol. 22, pp. 1553-56. 
17. K. Welpmann, Y.T. Lee, and M. Peters: Mater Sci. and Eng. A, 1990, vol. 129, pp. 21-34.

18. S.A. Vincent: Master's Thesis, LBL 24443, University of California, Berkeley, CA, Dec. 1987.

19. P.E. Johnson, J.H. Schmitt, S.A. Vincent, and J.W. Morris, Jr.: Scripta Metall., 1990, vol. 24, pp. 1447-52.

20. P.E. Johnson: PhD Thesis, University of California, Berkeley, CA, June 1991.

21. R.J. Bucci, R.C. Malcolm, E.L. Colvin, S.J. Murtha, and R.S. James: Final Report No. NSWC TR 89-106, Aluminum Company of America, Alcoa Center, PA, Sept. 1989.

22. A.K. Vasudèvan, W.G. Fricke, Jr., R.C. Malcolm, R.J. Bucci, M.A. Przystupa, and F. Barlat: Metall. Trans. A. 1988, vol. 19A, pp. 731-32.

23. A.K. Vasudèvan, W.G. Fricke, Jr., M.A. Przystupa, and S. Panchanadeeswaran: in 8th Int. Conf. on Textures of Materials, J.S. Kallend and G. Gottstein, eds., TMS, Warrendale, PA, 1988, pp. 1071-77.

24. R.J. Rioja, B.A. Cheney, R.S. James, J.T. Staley, and J.A. Bowers: StructureProperty Relationships in Al-Li Alloys: Plate and Sheet Products, Aluminum Corporation of America, Alcoa Center, PA, March 1989. 

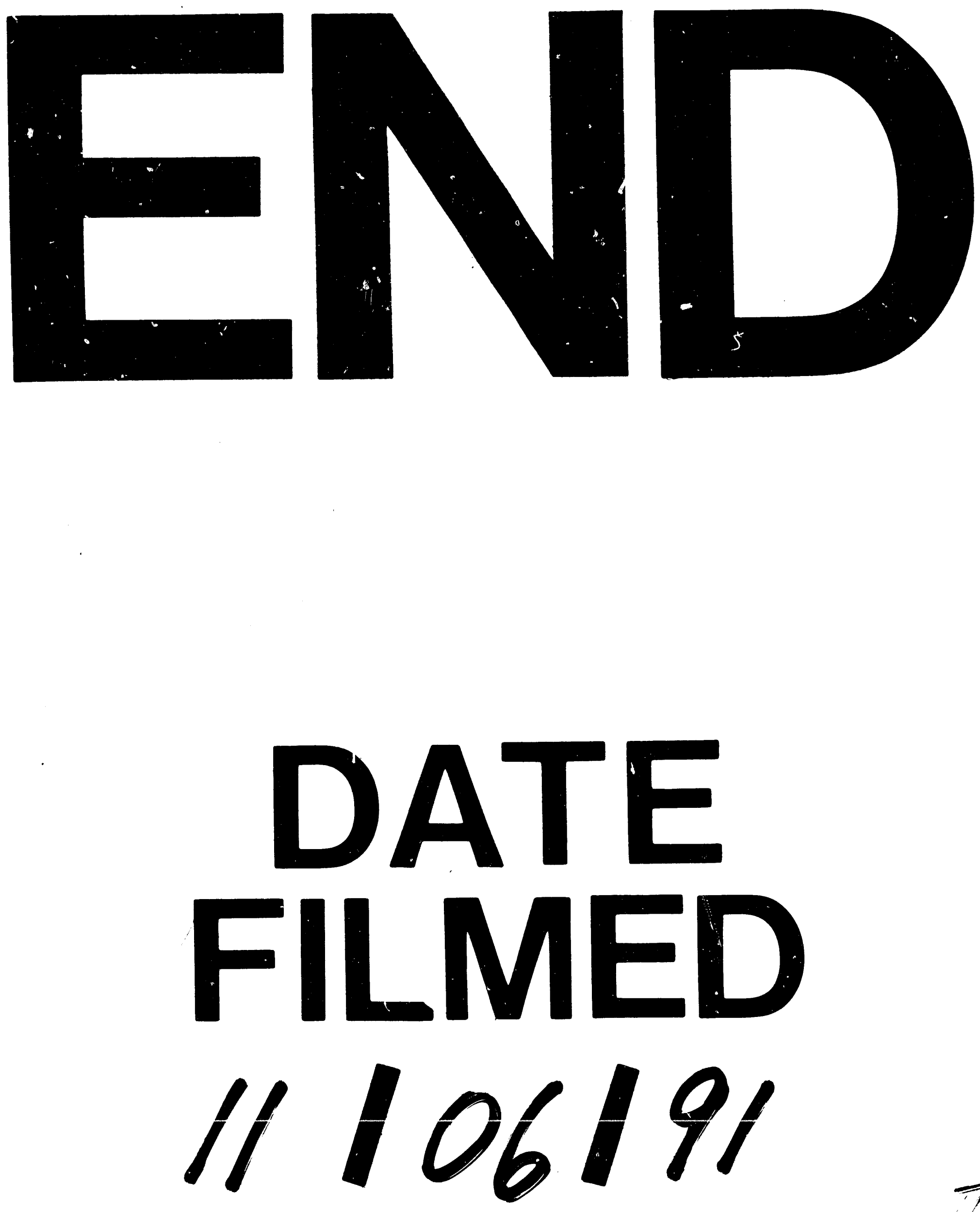

II 
